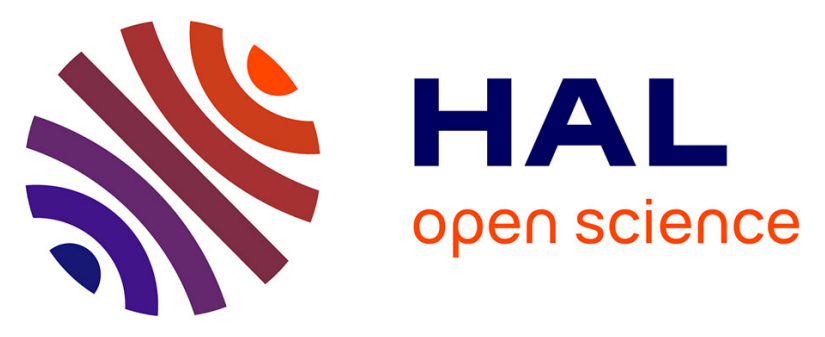

\title{
Invasive lobular carcinoma of the breast: MRI pathological correlation following bilateral total mastectomy.
}

\author{
Aude Stivalet, Alain Luciani, Frederic Pigneur, Thu Ha Dao, Pauline
} Beaussart, Zahira Merabet, Julie Perlbarg, Evelyne Meyblum, Laurence

Baranes, Elie Calitchi, et al.

\section{To cite this version:}

Aude Stivalet, Alain Luciani, Frederic Pigneur, Thu Ha Dao, Pauline Beaussart, et al.. Invasive lobular carcinoma of the breast: MRI pathological correlation following bilateral total mastectomy.. Acta Radiologica, 2012, 53 (4), pp.367-75. 10.1258/ar.2012.110477 . inserm-00709447

HAL Id: inserm-00709447 https://www.hal.inserm.fr/inserm-00709447

Submitted on 18 Jun 2012

HAL is a multi-disciplinary open access archive for the deposit and dissemination of scientific research documents, whether they are published or not. The documents may come from teaching and research institutions in France or abroad, or from public or private research centers.
L'archive ouverte pluridisciplinaire HAL, est destinée au dépôt et à la diffusion de documents scientifiques de niveau recherche, publiés ou non, émanant des établissements d'enseignement et de recherche français ou étrangers, des laboratoires publics ou privés. 
Invasive lobular carcinoma of the breast: MRI-pathological correlation

following bilateral total mastectomy

Aude Stivalet ${ }^{1}, \mathrm{MD}$; Alain Luciani ${ }^{1,2}, \mathrm{MD}, \mathrm{PhD}$; Frederic Pigneur ${ }^{1}$, MD; Thu Ha Dao ${ }^{1}$, MD; Zahira Merabet ${ }^{3}$, MD; Julie Perlbarg ${ }^{4}$; Christophe Lepage ${ }^{5}$, MD; Elie Calitchi ${ }^{6}$, MD; Yazid Belkacemi ${ }^{6}, \mathrm{MD}, \mathrm{PhD}$; Laurent Lantieri ${ }^{5}, \mathrm{MD}, \mathrm{PhD}$; Alain Rahmouni ${ }^{1}, \mathrm{MD}$, PhD.

${ }^{1}$ AP-HP, Groupe Henri Mondor Albert Chenevier, Imagerie Medicale, Creteil, F94010, France

${ }^{2}$ INSERM Unite U 955, Equipe 17, Universite Paris Est Creteil, Creteil, F-94010, France

${ }^{3}$ AP-HP, Groupe Henri Mondor Albert Chenevier, Pathology, Creteil, F-94010,

France

${ }^{4}$ AP-HP, Groupe Necker, Biotatistic department, Paris, 75015, France

${ }^{5}$ AP-HP, Groupe Henri Mondor Albert Chenevier, Plastic Surgery, Creteil, F-94010,

France

${ }^{6}$ AP-HP, Groupe Henri Mondor Albert Chenevier, Radiotherapy, Creteil, F-94010,

France

Address for correspondence / reprint requests:

Alain Luciani MD, PhD

AP-HP, Groupe Henri Mondor Albert Chenevier, Imagerie Médicale

CHU Henri Mondor

51 Avenue du Marechal de Lattre de Tassigny

94010 Creteil Cedex

France

Tel. +33149814631

Fax. +33149812632

Mail: alain.luciani@hmn.aphp.fr 


\section{Invasive lobular carcinoma of the breast: MRI-pathological correlation following bilateral total mastectomy}

\section{Abstract:}

Background: Invasive lobular carcinoma (ILC) is more often multifocal and bilateral than invasive ductal carcinoma. MRI is usually recommended for detection of all ILC sites. The performance of known diagnostic breast MRI criteria for ILC characterization has not been evaluated to date using bilateral mastectomy specimens as gold standard.

Purpose: To determine the value of BI-RADS $2006 \mathrm{MRI}$ criteria for ILC detection and characterization, using pathological examination of bilateral mastectomy specimens as the reference standard.

Material and Methods: Between 2004 and 2007, we retrospectively included all patients with pathologically documented ILC referred to our institution for bilateral mastectomy and preoperative bilateral breast MRI. The location, diameter and characteristics (BI-RADS) of all lesions were compared with pathological findings. The sensitivity and positive predictive value of bilateral breast MRI for the diagnosis of ILC were calculated. Association of MRI BI-RADS categorical variables and characterization of ILC were assessed (Fisher exact test).

Results: Among 360 patients treated for ILC in 2004-2007, 15 patients qualified for this study. Thirty-one ILC foci were found on pathological examination (30 ipsilateral and 1 contralateral tumor; mean diameter $23 \mathrm{~mm}$; range 2 to $60 \mathrm{~mm}$ ) and all were identified on MRI, with $90 \%$ of masses and $10 \%$ nonmasslike enhancements; MRI features significantly associated with ILC included absence of smooth margins $(p=0,02)$ and rim-shaped enhancement $(p=0,039)$. Enhancement kinetics of the 31 
foci were evenly distributed among washout, plateau and persistent profiles. Eleven additional lesions were seen on MRI, mainly corresponding to fibrocystic disease; $91 \%$ presented as masses and $9 \%$ had a washout profile.

Conclusion: Based on the 2006 BI-RADS criteria, breast MRI shows a high sensitivity for ILC detection, at the expense of a $26 \%$ false positive rate, suggesting that a pathological proof by US- or MR-guided biopsy is required in case of suspicious MRI images in this context.

Keywords (MeSH): Breast Neoplasms, Lobular Neoplasm, Magnetic Resonance Imaging 
Invasive lobular carcinoma (ILC) is the second most common breast malignancy after invasive ductal carcinoma (IDC), accounting for 5 to $20 \%$ of all breast cancers ( $1-3$ ). Pathologically, ILC is characterized by diffuse infiltrative growth (4), with a stroma infiltrated by tumor cells arranged in a single row and no associated desmoplastic reaction (5), hindering its diagnosis by imaging methods (6). In Hilleren et al. study of 137 mammographies in patients with ILC (7), the findings were normal or showed only subtle abnormalities in $20 \%$ of cases, while the reported sensitivity of breast ultrasound for ILC ranges from 68 to $88 \%(3,5)$.

Because of its diffuse infiltrative growth, ILC is generally larger than IDC at diagnosis (8). ILC is also more often multifocal (several lesions in the same quadrant) or multicentric (several lesions or one large lesion affecting more than one quadrant) than IDC $(3,5,9)$, reaching up to $50 \%$ of multifocal/multicentric forms $(7,10)$ compared to reported $19 \%$ rates in IDC (10). ILC also has a greater tendency than IDC to be bilateral, with rates of 6 to $20 \%$ and $2 \%$, respectively (11).

Positive pathological margins after conservative surgery are more frequent in ILC than in IDC (8), leading to more frequent re-excision and local recurrence risk (12). Some authors have suggested that optimal pre-operative staging of ILC, including breast MRI, could improve patient outcome (12). MRI has been described as one of the most appropriate tools for ILC staging (3), because of its high sensitivity for ILC detection and staging (ranging from 95\% (13) to 100\% (14)) and its high negative predictive value (NPV) (ranging from 95\% (13) to 100\% $(2,5,6,14)$ ). However, these values were based on core needle biopsies (CNB), lumpectomy or ipsilateral mastectomy specimens. On CNB, it can be difficult to distinguish ILC from lobular neoplasia (LN), which comprises two subtypes, namely lobular carcinoma in situ (LCIS) and atypical lobular hyperplasia (ALH). In Brem et al. study, 23\% of 164 
lesions classified as lobular neoplasia on CNB in fact corresponded to true neoplastic lesions (DCIS or ILC) after surgical excision (15), and some authors thus recommend excision biopsy when LN is diagnosed on CNB $(11,16,17)$.

Only few studies have examined the correlation between enhancing lesions on MRI and pathological examination of the surgical excision specimen $(5,13,14)$. Likewise, no correlation studies of bilateral mastectomy specimens and MRI findings have been reported in this setting.

The aim of this study was to determine the value of MRI for ILC detection and characterization, based on the $2006 \mathrm{BI}$-RADS criteria, using pathologic examination of bilateral total mastectomy specimens as the reference standard. 


\section{MATERIAL AND METHODS}

\section{Study cohort}

Between 2004 and 2007, 360 patients were diagnosed with ILC in our institution. We retrospectively included 15 women, with a mean age of 55 (range 38-66) with CNBproven ILC who were treated by bilateral total mastectomy and who underwent presurgical bilateral breast MRI. Among those 15 women, 8 had known risk factors for breast cancer including 5 patients with a familial history of breast cancer and 3 patients who received post-menopausal hormonal therapy for 5 years. Nine women were referred to our institution because of clinical symptoms and 6 because of an abnormal conventional (mammographic or sonographic) imaging screening. Mammograms were abnormal in 11 cases and sonography was abnormal in 13 cases. Bilateral mastectomy was indicated for surgical and aesthetic reasons in 11 cases including small breasts ( $\mathrm{n}=7$ cases) and optimization of post-operative breast symmetry $(n=4)$. Four women opted for prophylactic bilateral mastectomy in order to avoid close post-operative follow-up. All decisions were approved by a multidisciplinary board of surgeons, oncologists, radiologists, psychologists and radiation oncologists $(18,19)$. All patients had breast reconstruction, immediately in 14 cases and one year later in one case.

The mean interval between bilateral breast MRI and bilateral mastectomy was 2 months (0.5-3.5 months, median of 1.5 months) in 13 cases. In the 2 patients treated by neoadjuvant chemotherapy, respective intervals between surgery, prechemotherapy MRI and preoperative MRI were 6 and 1.5 months in one case, and 12 and 2.5 months in the other case. 
All patients were alive and free of recurrence after a mean follow-up period of 56 months (range 28-73). The median period of disease-free survival was 56 months (range 28-73).

\section{Pathology}

Pathological analysis of bilateral mastectomy specimens was based on international criteria (20), and was performed by the same senior pathologist with 10 years' experience in breast pathology. Mastectomy specimens were carefully palpated and all indurated areas were located (quadrants, superficial or deep area of breast) and removed. After that, mastectomy specimens were sliced entirely every centimeter in a transversal plane and all dystrophic or indurated areas were removed. Additional samples were systematically taken from the nipple skin and behind the areola.

Three samples of each dystrophic or indurated area were prepared from each tumor, including one transecting the maximum diameter of the tumor. All sections were analyzed macroscopically and then microscopically after hematoxillin-eosin (HE) staining. The maximum diameter and quadrant location of each tumor were recorded. In case of several closely located multi-focal or multi-centric tumors, the recorded maximum pathological diameter was defined as the largest distance between the two most distant lesions. The type of the neoplasm (ILC, IDC, or ductal carcinoma in situ (DCIS)) was determined. The quadrant location of lobular neoplasia (LN) associated with ILC was also noted and classified as LCIS (lobular carcinoma in situ) or ALH (atypical lobular hyperplasia) (17). The quadrant location of benign lesions such as fibrocystic disease and fibroadenoma was also recorded. 


\section{Breast MRI}

\section{- MRI protocol}

Bilateral breast MRI was performed on a 1.5T system (Siemens Avanto®, Erlangen, Germany), using a four-channel phased array coil, in keeping with international guidelines (21). Sagittal T1 fast spin echo (TR 530msec; TE9.8msec; FOV (field of view) of $23 \times 17 \mathrm{~cm}$, matrix of $384 \times 158$, slice thickness of $4 \mathrm{~mm}$ ); axial inversion recovery turbo spin echo T2 sequences (TR: $9000 \mathrm{msec}$, TE: $70 \mathrm{msec}$, TI (time of inversion): 120 msec, FOV $32 \times 32$, matrix 384 × 307, slice thickness: $4 \mathrm{~mm}$ ) were acquired. 3D fast gradient echo (Fast Low Angle SHot) fat saturated T1 sequences (TR: 11 msec, TE: 5.6 msec, FOV: $28 \times 28$, matrix 384 x 307, slice thickness: 3D $3.3 \mathrm{~mm}$ ) were acquired once before and 7 times after bolus injection of $0.2 \mathrm{mmol} / \mathrm{kg}$ gadoteric acid (Dotarem®, Guerbet, Aulnay, France) at a $3 \mathrm{ml} / \mathrm{sec}$ rate, flushed with $20 \mathrm{ml}$ of saline administered by a power-injector. The temporal resolution for each repetition was 49 seconds. Subtractions were obtained from unenhanced and enhanced dynamic 3D fast gradient echo T1 sequences. The last acquisition obtained was a sagittal T1 fast spin echo post-gadolinium sequence (TR: 550, TE: 9.8, FOV: $23 \times 17$, matrix $384 \times 158$, slice thickness: $4 \mathrm{~mm}$ ).

\section{- Image analysis}

All images were retrieved from the local PACS system and analyzed with Advantage Windows software version 4.4 (GE Healthcare, Milwaukee, WI, USA) by two radiologists (a junior resident with one year of experience and a senior radiologist with ten years of experience in breast imaging), who were aware of the diagnosis of ILC but blinded to clinical and pathological data. All images were analyzed by consensus. In case of discordance, a consensus was reached with a third radiologist with 15 years of experience in breast MRI. All images were interpreted according to 
2006 BI-RADS criteria, including morphological criteria on unenhanced T1 WI and T2WI images and enhancement and kinetic profiles following gadolinium chelates injection (21-23). The criteria are summarized in Annex 1.

\section{MRI-pathological correlation}

All MRI were interpreted independently from pathological data, MRI abnormalities were matched retrospectively with pathologic data on the basis of their maximum diameter and quadrant location described in the pathologic reports. In the two patients who received neoadjuvant chemotherapy, maximum tumor diameter was evaluated on preoperative MR images. Shape, margins (for masses), distribution of non-masslike enhancements and dynamic profiles were evaluated on MR images acquired before chemotherapy. The sensitivity and positive predictive value (PPV) of bilateral breast MRI for the diagnosis of ILC were calculated, with pathological findings as the reference standard. Cases of discordance were analyzed.

\section{Statistics}

Correlation between the diameters of ILC found on MR and pathological measurements taken as gold standard was assessed (Spearman). The ILC diameter was used when the neoplasia was unifocal and the largest diameters of all ILC sites from external border to external border of the two most distant lesions- was used when the neoplasia was multifocal or multicentric.

Comparisons of MRI BI-RADS categorical variables between ILC and false positive were performed with the Fisher exact test. All statistical analyses were conducted using R Software (http://cran.r-project.org). 


\section{RESULTS}

\section{Pathological findings}

Thirty-one foci of ILC were identified on pathology (Table 1). Seven patients had unifocal ILC (47\%), 6 patients had multicentric/multifocal ILC (40\%) and 2 patients had bilateral breast cancer (13\%), including one patient with one ILC tumor in each breast (patient 11), and one patient with 2 ILC in one breast and DCIS in the other breast (patient \#3).

Nine $(60 \%)$ of the 15 patients had lobular neoplasia in association with ILC, including the patient (patient \#11) with bilateral ILC, who presented with bilateral lobular neoplasia. Two patients had ALH and 7 patients had LCIS: all these 9 foci were located no further than $1 \mathrm{~cm}$ from ILC foci.

MRI-pathological correlation

All 31 ILC foci were identified on MRI (Table 1), as 28 masses and 3 non-masslike enhancements. Mean MRI diameter of ILC was $27 \mathrm{~mm}$ (range 9-65) and pathological mean ILC diameter was $23 \mathrm{~mm}$ (range 2-60) with excellent correlation Spearman correlation coefficient $r=0.92(95 \%$ confidence interval $0.78-1) ; p<0.0001$ (Fig. 1). MRI showed a mean diameter over-estimation of $4.43 \pm 4.38 \mathrm{~mm}$. All ILC foci enhanced following Gd-chelates injection, and all mass lesions had irregular or spiculated margins. No ILC presented smooth margins $(p=0,02)$. Ten ILC masses showed rim-shaped enhancement (36\%), 16 had homogeneous enhancement (57\%) and 2 had heterogeneous enhancement (7\%). Rim-shaped enhancement appeared as a distinctive feature of ILC $(p=0,039)$. Of the 3 non-masslike enhancements, one had a ductal distribution with stippled internal enhancement, and two had a focal distribution with heterogeneous enhancement. The enhancement kinetics of these 31 ILC lesions, including masses and non-masslike enhancements, were evenly 
distributed $(p=0,36)$, with 10 wash-out (32.5\%), 10 plateau (32.5\%) and 11 persistent profiles (35\%) (Figs. 2 and 3).

Using $2006 \mathrm{BI-RADS}$ criteria, 11 additional MRI abnormalities in 6 patients were wrongly classified as ILC (Tables 1 and 2; Figs. 4 and 5), corresponding either to fibrocystic disease $(n=8)$, fibroadenoma $(n=1)$ LCIS $(n=1)$ or DCIS $(n=1)$. Five falsepositive (FP) abnormalities were seen in the ipsilateral breast of 4 patients, one patient had 4 contralateral FP abnormalities (patient \#8), and one patient (patient \#3) had one ipsilateral and one contralateral FP abnormality. The false-positive abnormalities corresponded to 10 masses (91\%) and 1 nonmasslike enhancement (9\%) with a mean diameter of $9 \mathrm{~mm}$ (range 5-16). All enhanced after Gd-chelates injection. The enhancement kinetics of these $11 \mathrm{FP}$ lesions corresponded to 1 washout (9\%), 4 plateau (36\%) and 6 persistent profiles (55\%). Five FP masses had spiculated margins (50\%), 2 had irregular margins $(20 \%)$ and 3 had smooth margins (30\%). Presence of smooth margins appeared as a distinctive feature of false positive finding $(p=0,039)$.

Based on lesion-to-lesion correlation, the FP rate of MRI for ILC diagnosis was $26 \%$ (11/42). Based on 2006 BI-RADS criteria, the sensitivity of MRI for ILC detection was $100 \%$. The PPV of MRI for ILC detection was 74\% (31/42) overall, with an ipsilateral PPV of $83 \%(30 / 36)$ and a contralateral PPV of $17 \%(1 / 6)$. If DCIS was included in the calculation of the PPV of MRI for neoplastic foci, the contralateral PPV reached $33 \%(2 / 6)$.

When excluding known ILC from the analysis, the PPV of BI-RADS 4 and 5 additional suspicious images detected on MR for ILC diagnosis was 59\% (16/27); if DCIS was included as true positive MRI findings, the PPV of MR suspicious images reached $63 \%(17 / 27)$. As a result, additional neoplasia foci were detected in $47 \%$ $(7 / 15)$ of the study population. 


\section{DISCUSSION}

This MRI pathological study based on bilateral mastectomy specimens confirms the known sensitivity of preoperative MRI BI-RADS criteria for ILC detection and characterization, previously reported using only pathological examination of CNB or lumpectomy specimens $(24,25)$. However, the sensitivity figures might have been overestimated in this study because all radiologists were aware of an existing ILC proven on biopsy. MRI features significantly associated with ILC diagnosis included absence of smooth margins and rim enhancement, figures similar to those reported by Kim et al (26).

A $26 \%$ FP rate was found in our study using 2006 BI-RADS criteria, similar to that reported by Berg et al. (25). Fibrocystic disease accounted for most of these false positive findings, data similar to that of Baltzer et al. (27). Washout enhancement profiles were present in $32 \%$ of ILC lesions. Only one focus of fibrocystic disease displayed a washout curve, yielding a 91\% PPV of washout for ILC. Similar figures have been reported by Kinkel et al., suggesting that enhancement kinetics can help to distinguish between benign lesions and ILC (28).

Multifocal and/or multicentric ILC lesions were present in $40 \%$ of our patients. All ILC sites were detected on MRI, which is rarely the case of conventional mammograms or sonograms $(3,25)$. Moreover, some studies $(29,30)$ have suggested that the rate of local recurrences is higher in patients who undergo re-excision than in patients who are initially successfully treated, and our findings therefore imply that preoperative MRI could improve local control (12).

The overall PPV of breast MRI interpreted with 2006 BI-RADS criteria was $74 \%$, a figure close to that previously reported (5). However, although the prevalence of multifocal/multicentric ILC in our study matched that of previous studies $(4,29)$, only 
one contralateral ILC lesion was found in our bilateral mastectomy specimens. We acknowledge that we did not include all consecutive patients with ILC who underwent breast MRI at our institution, but rather only patients who underwent bilateral mastectomy, providing a unique pathological correlation. Our aim was indeed not to determine the prevalence of contra-lateral lesion, but rather to confirm the known sensitivity of breast MRI in ILC detection not only on biopsy or follow-up data. This selection bias could explain in part the low contralateral PPV of breast MRI for ILC detection (17\%) in our study $(14-17,21)$. Furthermore, we focused solely on the detection of ILC, and not all neoplastic lesions, which further lowered the contralateral PPV, DCIS being considered as a false-positive finding. Given the $100 \%$ sensitivity and $26 \%$ false-positive rate of breast MRI in our study, atypical MRI findings, especially in the contralateral breast, should be pathologically documented by second-look US- or MR-guided biopsy. Indeed, several studies confirm that the high false positive rate of MRI for ILC detection is still a challenge; our results further highlight that suspicious images on breast MRI should be documented on pathology before any therapeutic decision $(10,13,14)$.

Lobular neoplasia was strongly associated with ILC on pathological analysis in our study. Elsheikh et al reported lobular neoplasia in $27 \%$ of patients with invasive cancer (IDC and ILC) (16). Some authors have underlined the difficulty of distinguishing lobular neoplasms from ILC on CNB (15), while other consider lobular neoplasia to be a risk factor or even an indolent precursor of ILC, warranting its surgical excision (6). In our study, all foci of lobular neoplasia were located no further than $1 \mathrm{~cm}$ from ILC foci. Thus, the detection of lobular neoplasia on CNB may point to the presence of closely located ILC foci. Besides, it can also explain why diameters of ILC on MR were overestimated compared to pathology in most of the cases but that the overestimation is relatively constant and mild, and doesn't increase with the diameter of the tumor. 
One limit of this study is its retrospective design, which did not allow pathological examination to be guided by MRI. The small number of patients is also a drawback, but bilateral mastectomy is rarely indicated for patients with unifocal, multifocal or multicentric ILC. To our knowledge, our study is the first to provide pathological correlations based not only on follow-up and CNB but rather on full mastectomy specimens. As previously mentioned, the sensitivity of MRI for ILC might have been over-estimated, because the radiologists were aware that each patient had at least one focus of ILC detected on CNB. Our study design was however not intended to provide prevalence data of ILC. PPV of additional neoplastic lesions discovered on $\mathrm{MRI}$ is of critical importance in the clinical management of ILC patients. Our study based on analysis of bilateral mastectomy specimen lead to the detection of new sites of tumor for $47 \%$ of the 15 patients. Again, these figures could have been impacted by the selection bias: only patients who underwent bilateral mastectomy were included. Thus the overall contralateral prevalence of ILC cannot be determined using this study. On the opposite, our findings suggest that all BI-RADS 4 and 5 suspicious MR findings shouldn't be overlooked as suggestive of ILC lesions (26\% of false positive lesions in our study) and require MR- or US-guided second-look biopsies $(10,13,14)$. Taken together, our data first confirm that bilateral breast MRI allows detection of all ILC foci, even with bilateral mastectomy specimens as the reference standard, but at the expense of additional invasive diagnostic procedures in order to rule out malignancy in equivocal contralateral abnormalities.

In conclusion, MRI showed sensitivity figures in-line with previously published data for additional ILC sites detection and characterization, using bilateral mastectomy specimens as the reference standard. $90 \%$ of ILC foci corresponded to masses, all of which had irregular or spiculated margins. MRI detected all multifocal, multicentric or bilateral ILC foci. However, the high false-positive rate (26\%) suggests that suspicious MRI images should be verified by US- or MRI-guided biopsy. 


\section{References:}

1. Del Frate $\mathrm{C}$, Borghese $\mathrm{L}$, Cedolini $\mathrm{C}$ et al. Role of pre-surgical breast MRI in the management of invasive breast carcinoma. Breast. 2007;16:469-481.

2. Caramella T, Chapellier C, Ettore F, Raoust I, Chamorey E, Balu-Maestro C. Value of MRI in the surgical planning of invasive lobular breast carcinoma: a prospective and a retrospective study of 57 cases: comparison with physical examination, conventional imaging, and histology. Clin Imaging. 2007;31:155161.

3. Mann RM, Hoogeveen YL, Blickman JG, Boetes C. MRI compared to conventional diagnostic work-up in the detection and evaluation of invasive lobular carcinoma of the breast: a review of existing literature. Breast Cancer Res Treat. 2008;107:1-14.

4. Cocquyt V, Van Belle S. Lobular carcinoma in situ and invasive lobular cancer of the breast. Curr Opin Obstet Gynecol. 2005;17:55-60.

5. Fabre Demard N, Boulet P, Prat X, Charra L, Lesnik A, Taourel P. Breast MRI in invasive lobular carcinoma: diagnosis and staging. J Radiol. 2005;86:10271034.

6. Lopez JK, Bassett LW. Invasive lobular carcinoma of the breast: spectrum of mammographic, US, and MR imaging findings. Radiographics. 2009;29:165176.

7. Hilleren DJ, Andersson IT, Lindholm K, Linnell FS. Invasive lobular carcinoma: mammographic findings in a 10-year experience. Radiology. 1991;178:149-154.

8. Paumier A, Sagan C, Campion L et al. Accuracy of conservative treatment for infiltrating lobular breast cancer: a retrospective study of 217 infiltrating lobular 
carcinomas and 2155 infiltrating ductal carcinomas. J Gynecol Obstet Biol Reprod (Paris). 2003;32:529-534.

9. Liberman L, Morris EA, Dershaw DD, Abramson AF, Tan LK. MR imaging of the ipsilateral breast in women with percutaneously proven breast cancer. AJR Am J Roentgenol. 2003;180:901-910.

10. Rodenko GN, Harms SE, Pruneda JM et al. MR imaging in the management before surgery of lobular carcinoma of the breast: correlation with pathology. AJR Am J Roentgenol. 1996;167:1415-1419.

11. Liberman L, Morris EA, Kim CM et al. MR imaging findings in the contralateral breast of women with recently diagnosed breast cancer. AJR Am J Roentgenol. 2003;180:333-341.

12. Mann RM, Loo CE, Wobbes T et al. The impact of preoperative breast MRI on the re-excision rate in invasive lobular carcinoma of the breast. Breast Cancer Res Treat. 2010;119:415-422.

13. Kneeshaw PJ, Turnbull LW, Smith A, Drew PJ. Dynamic contrast enhanced magnetic resonance imaging aids the surgical management of invasive lobular breast cancer. Eur J Surg Oncol. 2003;29:32-37.

14. Pediconi F, Catalano C, Roselli A et al. Contrast-enhanced MR mammography for evaluation of the contralateral breast in patients with diagnosed unilateral breast cancer or high-risk lesions. Radiology. 2007;243:670-680.

15. Brem RF, Lechner MC, Jackman RJ et al. Lobular neoplasia at percutaneous breast biopsy: variables associated with carcinoma at surgical excision. AJR Am J Roentgenol. 2008;190:637-641.

16. Elsheikh TM, Silverman JF. Follow-up surgical excision is indicated when breast core needle biopsies show atypical lobular hyperplasia or lobular carcinoma in situ: a correlative study of 33 patients with review of the literature. Am J Surg Pathol. 2005;29:534-543. 
17. Foster MC, Helvie MA, Gregory NE, Rebner M, Nees AV, Paramagul C. Lobular carcinoma in situ or atypical lobular hyperplasia at core-needle biopsy: is excisional biopsy necessary? Radiology. 2004;231:813-819.

18. Giuliano AE, Boolbol S, Degnim A, Kuerer H, Leitch AM, Morrow M. Society of Surgical Oncology: position statement on prophylactic mastectomy. Approved by the Society of Surgical Oncology Executive Council, March 2007. Ann Surg Oncol. 2007;14:2425-2427.

19. Goldflam K, Hunt KK, Gershenwald JE et al. Contralateral prophylactic mastectomy. Predictors of significant histologic findings. Cancer. 2004;101:1977-1986.

20. Fitzgibbons PL, Connolly JL, Page DL. Updated protocol for the examination of specimens from patients with carcinomas of the breast. Cancer Committee. Arch Pathol Lab Med. 2000;124:1026-1033.

21. ACR Breast imaging reporting and data system. 2003

22. Morris EA. Illustrated breast MR lexicon. Semin Roentgenol. 2001;36:238-249.

23. Tardivon AA, Athanasiou A, Thibault F, El Khoury C. Breast imaging and reporting data system (BIRADS): magnetic resonance imaging. Eur J Radiol. 2007;61:212-215.

24. Bedrosian I, Mick R, Orel SG et al. Changes in the surgical management of patients with breast carcinoma based on preoperative magnetic resonance imaging. Cancer. 2003;98:468-473.

25. Berg WA, Gutierrez L, NessAiver MS et al. Diagnostic accuracy of mammography, clinical examination, US, and MR imaging in preoperative assessment of breast cancer. Radiology. 2004;233:830-849.

26. Kim SJ, Morris EA, Liberman L et al. Observer variability and applicability of BIRADS terminology for breast MR imaging: invasive carcinomas as focal masses. AJR Am J Roentgenol. 2001;177:551-557. 
27. Baltzer PA, Benndorf M, Dietzel M, Gajda M, Runnebaum IB, Kaiser WA. Falsepositive findings at contrast-enhanced breast MRI: a BI-RADS descriptor study. AJR Am J Roentgenol. 2010;194:1658-1663.

28. Kinkel K, Helbich TH, Esserman LJ et al. Dynamic high-spatial-resolution MR imaging of suspicious breast lesions: diagnostic criteria and interobserver variability. AJR Am J Roentgenol. 2000;175:35-43.

29. Aziz D, Rawlinson E, Narod SA et al. The role of reexcision for positive margins in optimizing local disease control after breast-conserving surgery for cancer. Breast J. 2006;12:331-337.

30. Menes TS, Tartter PI, Bleiweiss I, Godbold JH, Estabrook A, Smith SR. The consequence of multiple re-excisions to obtain clear lumpectomy margins in breast cancer patients. Ann Surg Oncol. 2005;12:881-885.

31. Kuhl C. The current status of breast MR imaging. Part I. Choice of technique, image interpretation, diagnostic accuracy, and transfer to clinical practice. Radiology. 2007;244:356-378. 
Tables

Table 1: MRI-pathological correlation analysis based on bilateral mastectomy specimens and the 2006 BI-RADS MRI criteria

\begin{tabular}{|c|c|c|c|c|c|c|c|c|c|c|c|}
\hline $\begin{array}{l}\text { Patient } \\
\text { Number }\end{array}$ & $\begin{array}{l}\mathrm{HL} / \\
\mathrm{CL}\end{array}$ & $\begin{array}{l}\text { M/ } / \\
\text { NM }\end{array}$ & Location & $\begin{array}{c}\text { Margins / } \\
\text { Distribution }\end{array}$ & $\begin{array}{l}\text { Internal } \\
\text { enhan- } \\
\text { cement }\end{array}$ & $\begin{array}{c}\text { Kinetic } \\
\text { of } \\
\text { early } \\
\text { phase } \\
<2 \text { min }\end{array}$ & $\begin{array}{c}\text { Curve } \\
\text { type on } \\
\text { delayed } \\
\text { phase } \\
(>5 \mathrm{~min})\end{array}$ & $\begin{array}{c}\text { Dia- } \\
\text { meter } \\
\text { on } \\
\text { MR } \\
(\mathrm{mm})\end{array}$ & $\begin{array}{l}\text { TP/ } \\
\text { FP }\end{array}$ & $\begin{array}{l}\text { Patho- } \\
\text { logy }\end{array}$ & $\begin{array}{c}\text { Dia- } \\
\text { meter } \\
\text { on } \\
\text { patho- } \\
\text { logy } \\
(\mathrm{mm})\end{array}$ \\
\hline 1 & $\mathrm{HL}$ & $M$ & SEQ & Irr & $\operatorname{Rim}$ & Med & 3 & 13 & 1TP & ILC & 12 \\
\hline 2 & $\mathrm{HL}$ & M & IEQ & spic & $\mathrm{Ho}$ & Low & 1 & 9 & 1TP & ILC & 10 \\
\hline 3 & $\begin{array}{l}\mathrm{HL} \\
\mathrm{HL} \\
\mathrm{HL} \\
\mathrm{CL}\end{array}$ & $\begin{array}{l}M \\
M \\
M \\
M\end{array}$ & $\begin{array}{c}\text { IEQ } \\
\text { IEQ } \\
\text { UInfQ } \\
\text { IEQ }\end{array}$ & $\begin{array}{c}\text { Spic } \\
\text { Spic } \\
\text { Spic } \\
\text { Smooth }\end{array}$ & $\begin{array}{l}\text { Rim } \\
\text { Rim } \\
\text { Ho } \\
\text { Ho }\end{array}$ & $\begin{array}{l}\text { Med } \\
\text { Med } \\
\text { Low } \\
\text { Low }\end{array}$ & $\begin{array}{l}2 \\
1 \\
1 \\
1\end{array}$ & $\begin{array}{c}22 \\
15 \\
7 \\
11\end{array}$ & $\begin{array}{l}\text { 1TP } \\
1 \mathrm{TP} \\
1 \mathrm{FP} \\
1 \mathrm{FP}\end{array}$ & $\begin{array}{c}\text { ILC } \\
\text { ILC } \\
\text { FD } \\
\text { DCIS }\end{array}$ & $\begin{array}{c}20 \\
10 \\
\text { NA } \\
6\end{array}$ \\
\hline 4 & $\begin{array}{l}\mathrm{HL} \\
\mathrm{HL} \\
\mathrm{HL} \\
\mathrm{HL} \\
\mathrm{HL}\end{array}$ & $\begin{array}{l}M \\
M \\
M \\
M \\
M\end{array}$ & $\begin{array}{c}\text { USupQ } \\
\text { SIQ } \\
\text { SIQ } \\
\text { SIQ } \\
\text { SIQ }\end{array}$ & $\begin{array}{c}\text { Irr } \\
\text { Spic } \\
\text { Spic } \\
\text { Spic } \\
\text { Irr }\end{array}$ & $\begin{array}{l}\mathrm{Rim} \\
\mathrm{Ho} \\
\mathrm{Ho} \\
\mathrm{Ho} \\
\mathrm{Ho}\end{array}$ & $\begin{array}{l}\mathrm{Hi} \\
\mathrm{Hi} \\
\mathrm{Hi} \\
\text { Low } \\
\text { Med }\end{array}$ & $\begin{array}{l}3 \\
3 \\
3 \\
1 \\
1\end{array}$ & $\begin{array}{l}16 \\
16 \\
10 \\
7 \\
6\end{array}$ & $\begin{array}{l}1 \mathrm{TP} \\
1 \mathrm{TP} \\
1 \mathrm{TP} \\
1 \mathrm{FP} \\
1 \mathrm{FP}\end{array}$ & $\begin{array}{l}\text { ILC } \\
\text { ILC } \\
\text { ILC } \\
\text { FD } \\
\text { FD }\end{array}$ & $\begin{array}{l}\} \\
335^{*} \\
\text { NA } \\
\text { NA }\end{array}$ \\
\hline 5 & $\mathrm{HL}$ & $M$ & IEQ & Irr\# & Rim\# & $\mathrm{Hi}$ & 3\# & $0 \# \#$ & 1TP & ILC & 0\#\# \\
\hline 6 & $\begin{array}{l}\mathrm{HL} \\
\mathrm{HL}\end{array}$ & $\begin{array}{l}M \\
M\end{array}$ & $\begin{array}{l}\text { SIQ } \\
\text { IIQ }\end{array}$ & $\begin{array}{l}\text { Spic } \\
\text { Spic }\end{array}$ & $\begin{array}{c}\mathrm{Rim} \\
\mathrm{Ho}\end{array}$ & $\begin{array}{l}\text { Low } \\
\text { Med }\end{array}$ & $\begin{array}{l}1 \\
1\end{array}$ & $\begin{array}{l}17 \\
10\end{array}$ & $\begin{array}{l}\text { 1TP } \\
\text { 1FP }\end{array}$ & $\begin{array}{l}\text { ILC } \\
\text { LCIS }\end{array}$ & $\begin{array}{r}17 \\
\text { NA }\end{array}$ \\
\hline 7 & $\mathrm{HL}$ & NM & $\mathrm{IEQ}$ & Focal & Het & $\mathrm{Hi}$ & 1 & 27 & 1TP & ILC & 20 \\
\hline 8 & $\begin{array}{l}\mathrm{HL} \\
\mathrm{HL} \\
\mathrm{HL} \\
\mathrm{HL} \\
\mathrm{HL} \\
\mathrm{HL} \\
\mathrm{HL} \\
\mathrm{CL} \\
\mathrm{CL} \\
\mathrm{CL} \\
\mathrm{CL}\end{array}$ & $\begin{array}{c}M \\
M \\
M \\
M \\
M \\
M \\
N M \\
M \\
M \\
M \\
N M\end{array}$ & $\begin{array}{c}\text { SEQ } \\
\text { SEQ } \\
\text { SEQ } \\
\text { UExtQ } \\
\text { UinfQ } \\
\text { Rar } \\
\text { IIQ } \\
\text { SIQ } \\
\text { USupQ } \\
\text { SEQ } \\
\text { USupQ }\end{array}$ & $\begin{array}{c}\text { Spic } \\
\text { Spic } \\
\text { Spic } \\
\text { Spic } \\
\text { Irr } \\
\text { Irr } \\
\text { Ductal } \\
\text { Irr } \\
\text { Smooth } \\
\text { Irr } \\
\text { Ductal }\end{array}$ & $\begin{array}{c}\text { Het } \\
\text { Ho } \\
\text { Ho } \\
\text { Rim } \\
\text { Rim } \\
\text { Het } \\
\text { Stip } \\
\text { Ho } \\
\text { Ho } \\
\text { Ho } \\
\text { Het }\end{array}$ & $\begin{array}{c}\mathrm{Hi} \\
\mathrm{Hi} \\
\mathrm{Hi} \\
\mathrm{Hi} \\
\mathrm{Hi} \\
\mathrm{Med} \\
\mathrm{Hi} \\
\mathrm{Hi} \\
\mathrm{Hi} \\
\mathrm{Hi} \\
\mathrm{Hi}\end{array}$ & $\begin{array}{l}3 \\
1 \\
1 \\
3 \\
2 \\
2 \\
2 \\
3 \\
2 \\
2 \\
2 \\
2\end{array}$ & $\begin{array}{c}15 \\
26 \\
5 \\
5 \\
24 \\
35 \\
15 \\
12 \\
5 \\
8 \\
16\end{array}$ & $\begin{array}{l}1 \mathrm{TP} \\
1 \mathrm{TP} \\
1 \mathrm{TP} \\
1 \mathrm{TP} \\
1 \mathrm{TP} \\
1 \mathrm{TP} \\
1 \mathrm{TP} \\
1 \mathrm{FP} \\
1 \mathrm{FP} \\
1 \mathrm{FP} \\
1 \mathrm{FP}\end{array}$ & $\begin{array}{l}\text { ILC } \\
\text { ILC } \\
\text { ILC } \\
\text { ILC } \\
\text { ILC } \\
\text { ILC } \\
\text { ILC } \\
\text { FD } \\
\text { FD } \\
\text { FD } \\
\text { FD }\end{array}$ & $\begin{array}{l}\} \\
\} \\
\} \\
\} \\
\} \\
\} \\
\} \\
\text { NA } \\
\text { NA } \\
\text { NA } \\
\text { NA }\end{array}$ \\
\hline 9 & $\mathrm{HL}$ & $M$ & SEQ & Spic\# & Rim\# & $\mathrm{Hi} \#$ & 2\# & $17 \# \#$ & 1TP & ILC & 15\#\# \\
\hline
\end{tabular}




\begin{tabular}{|c|c|c|c|c|c|c|c|c|c|c|c|}
\hline 10 & $\begin{array}{l}\mathrm{HL} \\
\mathrm{HL} \\
\mathrm{HL} \\
\mathrm{HL} \\
\mathrm{HL} \\
\mathrm{HL}\end{array}$ & $\begin{array}{l}M \\
M \\
M \\
M \\
M \\
M\end{array}$ & $\begin{array}{l}\text { SIQ } \\
\text { SIQ } \\
\text { SIQ } \\
\text { SIQ } \\
\text { SIQ } \\
\text { IIQ }\end{array}$ & $\begin{array}{l}\text { Spic } \\
\text { Spic } \\
\text { Spic } \\
\text { Spic } \\
\text { Spic } \\
\text { Spic }\end{array}$ & $\begin{array}{l}\mathrm{Ho} \\
\mathrm{Ho} \\
\mathrm{Ho} \\
\mathrm{Ho} \\
\mathrm{Ho} \\
\mathrm{Ho}\end{array}$ & $\begin{array}{l}\mathrm{Hi} \\
\mathrm{Hi} \\
\mathrm{Hi} \\
\mathrm{Hi} \\
\mathrm{Hi} \\
\mathrm{Hi}\end{array}$ & $\begin{array}{l}2 \\
2 \\
2 \\
2 \\
2 \\
2\end{array}$ & $\begin{array}{l}10 \\
11 \\
11 \\
12 \\
13 \\
10\end{array}$ & $\begin{array}{l}1 \mathrm{TP} \\
1 \mathrm{TP} \\
1 \mathrm{TP} \\
1 \mathrm{TP} \\
1 \mathrm{TP} \\
1 \mathrm{FP}\end{array}$ & $\begin{array}{l}\text { ILC } \\
\text { ILC } \\
\text { ILC } \\
\text { ILC } \\
\text { ILC } \\
\text { FD }\end{array}$ & $\begin{array}{l}\} \\
\} \\
\} \\
\} \\
{ }_{N A} \\
N 0^{*}\end{array}$ \\
\hline 11 & $\begin{array}{l}\mathrm{HL} \\
\mathrm{CL}\end{array}$ & $\begin{array}{l}M \\
M\end{array}$ & $\begin{array}{l}\text { SEQ } \\
\text { USupQ }\end{array}$ & $\begin{array}{c}\text { Irr } \\
\text { Spic }\end{array}$ & $\begin{array}{l}\text { Ho } \\
\text { Ho }\end{array}$ & $\begin{array}{l}\text { Low } \\
\text { Low }\end{array}$ & $\begin{array}{l}1 \\
1\end{array}$ & $\begin{array}{l}15 \\
10\end{array}$ & $\begin{array}{l}\text { 1TP } \\
1 \mathrm{TP}\end{array}$ & $\begin{array}{l}\text { ILC } \\
\text { ILC }\end{array}$ & $\begin{array}{l}6 \\
2\end{array}$ \\
\hline 12 & $\begin{array}{l}\mathrm{HL} \\
\mathrm{HL}\end{array}$ & $\begin{array}{c}\mathrm{NM} \\
\mathrm{M}\end{array}$ & $\begin{array}{c}\text { USupQ } \\
\text { IEQ }\end{array}$ & $\begin{array}{c}\text { Focal } \\
\text { Smooth }\end{array}$ & $\begin{array}{l}\text { Het } \\
\mathrm{Ho}\end{array}$ & $\begin{array}{l}\text { Low } \\
\text { Low }\end{array}$ & $\begin{array}{l}1 \\
1\end{array}$ & $\begin{array}{c}18 \\
6\end{array}$ & $\begin{array}{l}\text { 1TP } \\
1 \mathrm{FPP}\end{array}$ & $\begin{array}{l}\text { ILC } \\
\text { FA }\end{array}$ & $\begin{array}{l}7 \\
5\end{array}$ \\
\hline 13 & $\begin{array}{l}\mathrm{HL} \\
\mathrm{HL}\end{array}$ & $\begin{array}{l}M \\
M\end{array}$ & $\begin{array}{l}\text { SIQ } \\
\text { IEQ }\end{array}$ & $\begin{array}{l}\text { Spic } \\
\text { Spic }\end{array}$ & $\begin{array}{l}\mathrm{Ho} \\
\mathrm{Ho}\end{array}$ & $\begin{array}{l}\mathrm{Hi} \\
\text { Low }\end{array}$ & $\begin{array}{l}3 \\
1\end{array}$ & $\begin{array}{l}15 \\
20 \\
\end{array}$ & $\begin{array}{l}\text { 1TP } \\
\text { 1TP }\end{array}$ & $\begin{array}{l}\text { ILC } \\
\text { ILC }\end{array}$ & $\begin{array}{l}10 \\
20 \\
\end{array}$ \\
\hline 14 & $\mathrm{HL}$ & $M$ & SEQ & Spic & Rim & $\mathrm{Hi}$ & 3 & 23 & 1TP & ILC & 25 \\
\hline 15 & $\begin{array}{l}\mathrm{HL} \\
\mathrm{HL}\end{array}$ & $\begin{array}{l}M \\
M\end{array}$ & $\begin{array}{l}\text { SEQ } \\
\text { RAr }\end{array}$ & $\begin{array}{l}\text { Spic } \\
\text { Irr }\end{array}$ & $\begin{array}{l}\mathrm{Ho} \\
\mathrm{Ho}\end{array}$ & $\begin{array}{l}\mathrm{Hi} \\
\text { Low }\end{array}$ & $\begin{array}{l}3 \\
1\end{array}$ & $\begin{array}{c}25 \\
6\end{array}$ & $\begin{array}{l}\text { TP } \\
\text { TP }\end{array}$ & $\begin{array}{l}\text { ILC } \\
\text { ILC }\end{array}$ & \} 40 * \\
\hline
\end{tabular}

P: patient number; M: mass; NM: non-masslike enhancement; TP: true positive; FP: false positive; $\mathrm{HL}$ : ipsilateral to ILC; CL: contralateral to ILC; SEQ: supero-external quadrant; SIQ: supero-internal quadrant; IEQ: infero-external quadrant; IIQ: inferointernal quadrant; UinfQ: union of inferior quadrants; UintQ: union of internal quadrants; USupQ: union of superior quadrants; UExtQ: union of external quadrants; Rar: retroaureolar location; Irr: irregular margins; Spic: spiculated margins; Ductal: ductal distribution; Focal: focal distribution; Rim: rim-shaped internal enhancement; Ho: homoegeneous internal enhancement; Het: heterogeneous internal enhancement; Stip: stippled internal enhancement; Low: slow signal increase on early phase $(<2 \mathrm{~min}),<70 \%$ of enhancement ; Med: medium signal increase on early phase (<2min), between 70 and $100 \%$ of enhancement; Hi: high signal increase on early phase $(>2 \mathrm{~min}),>100 \%$ of enhancement; Type 1 : persistent profile on delayed phase; Type 2: plateau profile on delayed phase; Type 3: wash-out on delayed phase; ILC: invasive lobular carcinoma; DCIS: ductal carcinoma in situ; FD:

Fibrocystic Disease; LCIS: lobular carcinoma in situ; FA: fibroadenoma; NA: not available; *: The largest distance between the two most distant lesions was collected 
if ILC was multifocal/multicentric; \#: MRI characteristics of the lesions were collected before chemotherapy; \#\#: lesion diameter was collected after chemotherapy 
Table 2: Morphologic and kinetic profiles of ILC and false-positive lesions on MRI.

\begin{tabular}{|c|c|c|c|}
\hline & & ILC & FP \\
\hline $\mathrm{M} / \mathrm{NM}$ & $\bar{M}$ & $90 \%(28 / 31)$ & $91 \%(10 / 11)$ \\
\hline & NM & $10 \%(3 / 31)$ & $9 \%(1 / 11)$ \\
\hline$M$ margins & Spic & $75 \%(21 / 28)$ & $50 \%(5 / 10)$ \\
\hline & Irr & $25 \%(7 / 28)$ & $20 \%(2 / 10)$ \\
\hline & Smooth & $0 \%$ & $30 \%(3 / 10)$ \\
\hline M enhancement & $\operatorname{Rim}$ & $36 \%(10 / 28)$ & $0 \%$ \\
\hline & $\mathrm{Ho}$ & $57 \%(16 / 28)$ & $80 \%(8 / 10)$ \\
\hline & Het & $7 \%(2 / 28)$ & $20 \%(2 / 10)$ \\
\hline NM distribution & Focal & $67 \%(2 / 3)$ & $0 \%$ \\
\hline & Ductal & $33 \%(1 / 3)$ & $100 \%$ \\
\hline NM & Het & $67 \%(2 / 3)$ & $100 \%$ \\
\hline enhancement & Stippled & $33 \%(1 / 3)$ & 0 \\
\hline Kinetics & Type 1 curve & $35 \%(11 / 31)$ & $55 \%(6 / 11)$ \\
\hline & Type 2 curve & $32.5 \%(10 / 31)$ & $36 \%(4 / 11)$ \\
\hline & Type 3 curve & $32.5 \%(10 / 31)$ & $9 \%(1 / 11)$ \\
\hline
\end{tabular}

M: mass; NM: non-masslike enhancement; Spic: spiculated margins; Irr: irregular margins; Smooth: smooth margins; Focal: focal distribution; Ductal: ductal distribution; Rim: rim-shaped internal enhancement; Ho: homogeneous internal enhancement; Het: heterogeneous internal enhancement; Stippled: stippled internal enhancement; Curve type on delayed phase: 1: persistent profile on delayed phase; 2: plateau on delayed phase; 3 : wash-out on delayed phase. 
Figures:

Fig. 1- MRI and pathological ILC diameters. Scatter plot showing individual measurements of ILC performed on MRI with the pathological diameter of ILC as gold standard around the line of equality.

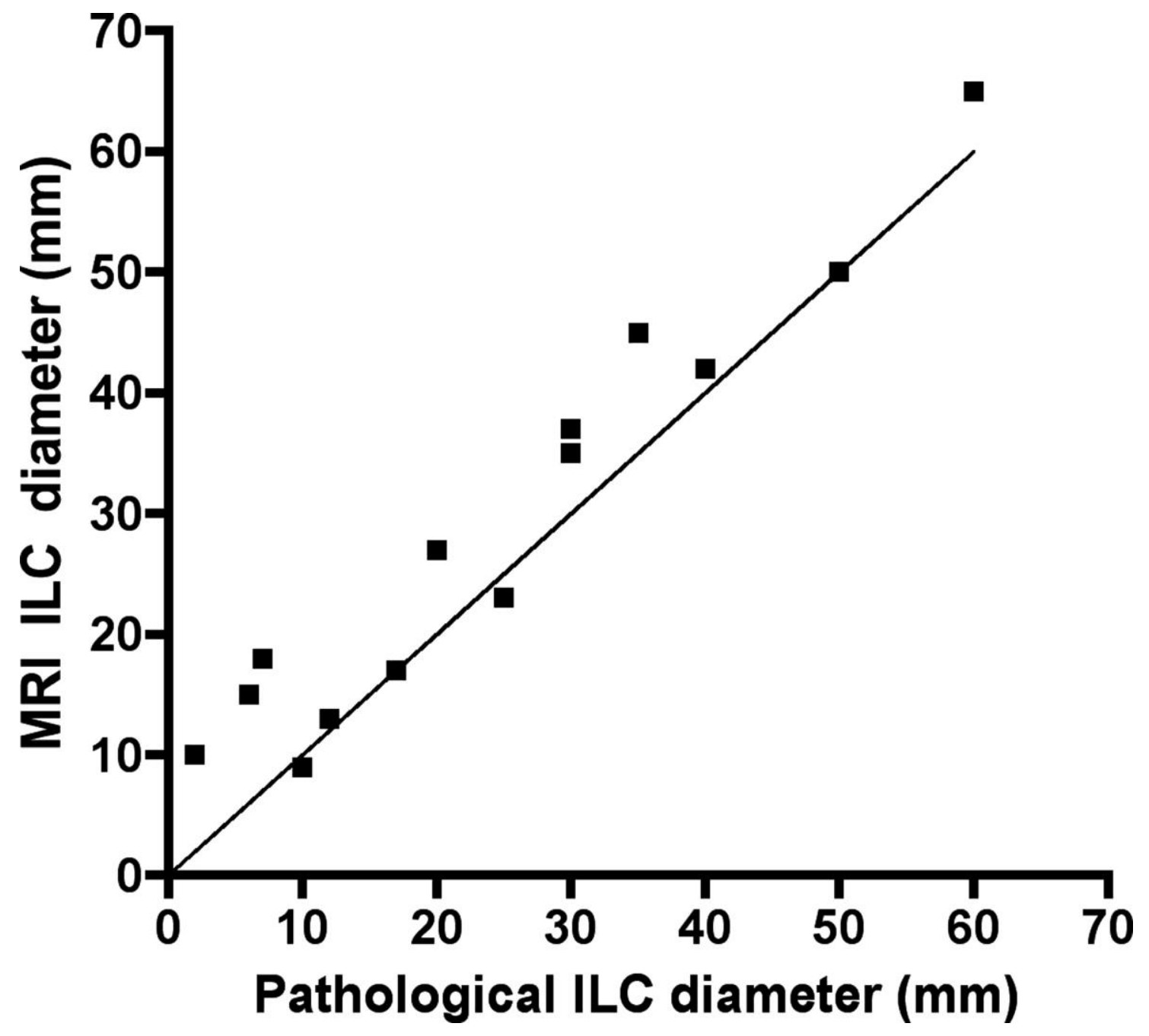


Fig. 2- 50-year-old woman with no personal or family history of breast cancer, with bifocal Invasive Lobular Carcinoma (ILC) of the right breast. MR images of the right breast showed two round masses with spiculated margins and with respective largest diameters of 22 and $15 \mathrm{~mm}$ (arrow and arrowhead) on sagittal T1WI (Fig. 2A), showing rim-shaped enhancement (arrow and arrowhead in Fig. 2B) after gadolinium chelates injection and type 2 curve (Fig. 2C); Lesions were defined as suspicious ILC lesions using 2006 BI-RADS MRI criteria. On pathology (x25) after HE staining, both tumors showed spiculated margins (arrows in Fig. 2D), and linear arrangement of ILC cells (Fig. 2D). 
Fig. 3- 58-year-old woman with a family history of breast cancer, with a 2-cm unifocal non-masslike enhancing Invasive Lobular Carcinoma (ILC) of the right breast. MR images of the right breast showed non-masslike enhancement, isointense on sagittal T1WI when compared to adjacent breast parenchyma (circle on Fig. 3A). The ILC non-masslike lesion exhibited a focal and heterogeneous enhancing pattern after gadolinium injection (Arrowheads on Fig. 3B) with a type 1 enhancement curve (Fig. 3C) that was identified as a true positive on 2006 BI-RADS MRI criteria. On pathology (x40) after HE staining, the tumor shows the linear file arrangement of infiltrative lobular carcinoma ("Indian file pattern") (black arrows in Fig. 3D). 
Fig. 4- 41-year-old woman with a family history of breast cancer, with multicentric Invasive Lobular Carcinoma (ILC) (4 sites of cancer spreading over 35mm) of the left breast, with a suspicious ipsilateral MR image: MR images of the left breast showed a mass with spiculated margins, hypointense on sagittal T1WI (arrowheads on Fig. 4A) with intense and homogeneous enhancement (arrow on Fig. 4B) and a type 2 curve, erroneously classified as suspicious on 2006 BI-RADS MRI criteria (false positive image). Pathology (x10) after HE staining showed cystic and dystrophic ducts (black arrows) surrounded by fibrosis, consistent with fibrocystic disease (Fig. $4 C)$. 
Fig. 5- 51-year-old woman with a family history of breast cancer, with a $15 \mathrm{~mm}$ unifocal Invasive Lobular Carcinoma (ILC) of the left breast and an additional suspicious MR image on the ipsilateral breast: MR images of the left breast showed a mass with spiculated margins, isointense on sagittal T1WI (arrowheads on Fig. 5A), with homogenous intense enhancement after gadolinium injection (arrow on Fig. 5B) and type 1 curve; the lesion was classified as suspicious using 2006 BI-RADS MRI criteria. Pathology (x40) after HE staining showed ducts filled and distended by noncohesive tumoral cells, consistent with lobular carcinoma in situ (Arrow on Fig. 5C). 


\section{Annex 1: 2006 BI-RADS criteria for MRI (21)}

Mass: A mass is a space-occupying tumor that has three dimensions. Usually, it has a visible correlate on precontrast T1- or T2-weighted images; Non-masslike enhancement: Non-masslike enhancement means that enhancement occurs in an area of the fibroglandular tissue that otherwise appears normal on precontrast images. There is no space-occupying effect. The enhancing area usually has no correlate on fat-suppressed or non-fat-suppressed T2-weighted images; Type1: kinetic curve showing persistant profile on delayed phase; Type 2: kinetic curve showing a plateau on delayed phase; Type 3: kinetic curve showing a wash out on delayed phase (31). 


\begin{tabular}{|c|c|c|}
\hline \multicolumn{3}{|l|}{ Mass } \\
\hline Shape & Margins & Internal enhancement \\
\hline Round & Smooth & Homogeneous \\
\hline Oval & Irregular & Heterogeneous \\
\hline Lobulated & Spiculated & Rim-shaped \\
\hline Irregular & & Enhanced internal septa \\
\hline & & Unenhanced internal septa \\
\hline & & Central enhancement \\
\hline \multicolumn{3}{|c|}{ Non-masslike enhancement } \\
\hline Distribution & Internal enhancement & Symmetry \\
\hline Focal & Homogeneous & Symmetrical \\
\hline Linear & Heterogeneous & Asymmetrical \\
\hline Ductal & Stippled & \\
\hline Segmental & Clumped & \\
\hline Regional & Reticular & \\
\hline Multiregional & & \\
\hline Diffuse & & \\
\hline \multicolumn{3}{|l|}{ Kinetics } \\
\hline Initial phase & Delayed phase & Type \\
\hline Slow & Persistant & 1 \\
\hline
\end{tabular}




\begin{tabular}{|l|l|c|}
\hline Medium & Plateau & 2 \\
Rapid & Wash out & 3 \\
\hline
\end{tabular}

